\title{
Influence of Laurolactam Content on the Clay Intercalation of Polyamide 6,12/Clay Nanocomposites Synthesized by Open Ring Anionic Polymerization
}

\author{
E. N. Cabrera Álvarez, L. F. Ramos de Valle, \\ F. J. Rodríguez González, F. Soriano-Corral, and R. E. Díaz De León \\ Polymer Processing Department, Centro de Investigación en Química Aplicada (CIQA), Boulevard Enrique Reyna, \\ No. 140, 25294 Saltillo, COAH, Mexico \\ Correspondence should be addressed to E. N. Cabrera Álvarez, enazareo@posgrado.ciqa.mx and \\ L. F. Ramos de Valle, devalle@ciqa.mx
}

Received 4 May 2012; Accepted 23 July 2012

Academic Editor: Sadhan C. Jana

Copyright (C) 2012 E. N. Cabrera Álvarez et al. This is an open access article distributed under the Creative Commons Attribution License, which permits unrestricted use, distribution, and reproduction in any medium, provided the original work is properly cited.

\begin{abstract}
In situ anionic homo- and copolymerization of caprolactam (CL) and laurolactam (LL) with sodium montmorillonite clay (NaMMT) was carried out using two different initiators, sodium caprolactamate (CLNa) and caprolactam magnesium bromide (CLMgBr). Degree of conversion and final molecular weight were used to assess the advancement and efficiency of the polymerization reaction and X-ray diffraction and electron microscopy were used to evaluate the sodium montmorillonite clay intercalation/exfoliation. The use of CLNa as initiator produced a higher conversion degree and molecular weight than the use of CLMgBr. Through DSC, it was observed that CLNa and CLMgBr tended to produce random and block copolymer structures, respectively, and either random or block, this eventually has an effect on the clay dispersion within the polymer matrix. In all cases, increasing the LL content produced a decrease in the conversion degree and in the molecular weight of the resulting polymer.
\end{abstract}

\section{Introduction}

Fast-activated anionic polymerization has been successfully used for the polymerization of lactams. The intended highpolymerization rate of the anionic polymerization is achieved by introducing an activator, which is a compound containing an $\mathrm{N}$-acyllactam structure. In this sense, sodium hydride in caprolactam [1] and sodium caprolactamate (CLNa) [2] have been used as initiators for the initiation stage.

The technology of the in situ polymerization with sodium montmorillonite clay (NaMMT) was first established at the Toyota laboratories via the hydrolytic polymerization of $\varepsilon$-caprolactam intercalated in a complex of 12-aminododecanoic acid-NaMMT, in order to obtain a polyamide $6 /$ clay nanocomposite (PA6/Clay) $[3,4]$. Combination of the in situ polymerization techniques with the anionic polimerization of lactams has been reported, where polyamide nanocomposites are readily obtained [5, 6]. Jung et al. [7] recently reported the obtaining of PA6/Clay nanocomposites via the in situ anionic polymerization of caprolactam (CL) with clay, using CLNa as initiator and $\mathrm{N}$-acetyl-caprolactam (ACL) as activator. While studying the synthesis of PA6/clay nanocomposites, Liu et al. [8] reported that when using NaMMT, they obtained exfoliated nanocomposites whereas when using organomodified montmorillonite they obtained intercalated nanocomposites. Ahmed and Lee [9] studied the effect of clay concentration on the mechanical and viscoelastic properties of PA6/clay nanocomposites synthesized via anionic polymerization.

On the other hand, studies on the synthesis of composites based on the in situ anionic copolymerization of CL and 
laurolactam (LL) with NaMMT have not received so much attention. In this sence, Ricco et al. [10] studied the copolymerization of CL with LL, using CLNa and sodium laurolactamate or a mix of both, as initiators, and found that the greatest conversion resulted when using CLNa. Budín et al. [11] studied the anionic copolymerization of CL with LL using either, CLNa or caprolactam magnesium bromide (CLMgBr) as initiators, and found that when using CLNa, there was a tendency to produce random copolymers, whereas when using CLMgBr, the tendency was to produce block copolymers. Although, the structure type of the copolymer was also dependant on the temperature of reaction and on the monomers molar ratio.

The purpose in this work, therefore, was to study the effect of the initiator type on the conversion degree and molecular weight of the final polymer, as well as the effect of the copolymer structure on the clay intercalation-exfoliation.

\section{Experimental}

2.1. Material. The materials used in this study were caprolactam (CL), from Univex; laurolactam (LL), from Aldrich; sodium caprolactamate (CLNa) in Caprolactam at $18.5 \mathrm{wt} \%$ concentration from Brüggemann Chemicals; caprolactam magnesium bromide $(\mathrm{CLMgBr})$ in caprolactam at $17 \mathrm{wt} \%$ concentration from Brüggemann Chemicals; $\mathrm{N}$-acetyl caprolactam (ACL) from Aldrich; sodium montmorillonite clay (NaMMT) from Southern Clay Inc.

2.2. Copolymerization. The in situ anionic polymerization was carried out in test tubes, where CL, LL, or a mix of both were introduced and heated to $180^{\circ} \mathrm{C}$. Thereafter, $0.5 \mathrm{~mol} \%$ of CLNa or CLMgBr was added as initiator, then, $2 \mathrm{wt} \%$ of NaMMT was added, and finally, $0.5 \mathrm{~mol} \%$ of $\mathrm{N}$-acetyl caprolactam was added as activator, all percentages with respect to the total mols of CL + LL. The reaction was allowed to proceed for $30 \mathrm{~min}$ in a nitrogen atmosphere. The copolymerizations of CL with LL were carried out using $100 / 0,80 / 20,60 / 40,40 / 60,20 / 80$, and $0 / 100 \mathrm{~mol} \%$ of CL/LL, respectively. Nanocomposites obtained were then grounded, purified through Soxhlet extraction with methanol, and vacuum-dried at $110^{\circ} \mathrm{C}$ for 8 hours.

2.3. Characterization. Conversion was determined gravimetrically by Soxhlet extraction with methanol of the material from the test tubes, where the reaction took place, for 24 hours, using a $2: 1$ methanol-water mixture as the solvent, in order to extract the unreacted monomers and initiators. Thereafter, the remaining material in the Soxhlet tube was dried at $110^{\circ} \mathrm{C}$ until constant weight. The conversion was taken as the final weight in the Soxhlet divided by the initial weight and multiplied by 100 .

An Alliance 2695 Gel Permeation Chromatograph, with a UV detector model $2487(248 \mathrm{~nm})$ and styragel columns, was used to determine the evolution of molecular weight of all samples. Samples were first dissolved in trifluoroacetic acid and run in the GPC at a flow rate of $1 \mathrm{~mL} / \mathrm{min}$.

$\mathrm{X}$-ray diffraction (XRD) analyses were carried out in a Siemens D5000 using an anode of CuK $\alpha$ X-ray of $1.54 \AA$ at
$35 \mathrm{Kv}$ and $25 \mathrm{~mA}$. Samples were scanned at diffraction angles from 2 to $12^{\circ}$ in $2(\theta)$. Runs were performed with a step size of $0.02^{\circ}$ and step time of $1.0 \mathrm{~s}$. Bragg's law $(n \lambda=2 d \sin \theta)$ was used to convert the data of diffraction angle $(2 \theta)$ to distance $(d)$. Samples for X-ray analysis were obtained from the compression molded process.

Differential Scanning Calorimetry (DSC) analysis was performed on a TA Instruments 2920 Modulated DSC to establish the thermal transitions and structural characteristics of all samples. Samples of ca $10 \mathrm{mg}$ were analyzed under a nitrogen atmosphere. Thermal analysis was carried out as follows: samples were first heated up to $250^{\circ} \mathrm{C}$ at a heating rate of $10^{\circ} \mathrm{C} / \mathrm{min}$ and then cooled down to $0^{\circ} \mathrm{C}$ at $-10^{\circ} \mathrm{C} / \mathrm{min}$. Finally, samples were heated again up to $250^{\circ} \mathrm{C}$ at $10^{\circ} \mathrm{C} / \mathrm{min}$.

The clay structural organization was studied through STEM observations using a Jeol-JSM7104F electron microscope equipped with STEM modulus and a field emission gun, at an accelerating voltage of $30 \mathrm{kV}$, using a LEI (low electron image) detector. Ultrathin sections for STEM analysis were previously cut from compression molded samples with a diamond knife at $-30^{\circ} \mathrm{C}$ using a Leica cryogenic ultramicrotome.

\section{Results and Discussion}

3.1. Physicochemical Properties. Figure 1 shows the conversion and molecular weight of the in situ anionic homo- and copolymerizations of CL, LL, and CL with LL, respectively. The NaMMT content was kept at $2 \mathrm{wt} \%$. All polymerizations were carried out for $30 \mathrm{~min}$, using either CLNa or CLMgBr as initiators.

It can be observed in Figure 1(a), that the highest conversion was achieved during the homopolymerization of CL for obtaining polyamide 6/NaMMT (PA6/NaMMT), independently of the initiator used. Also, it was observed that conversion decreased as the LL/CL ratio increased in the nanocomposites of poly (caprolactam-co-laurolactam)/NaMMT (PA6:12/NaMMT), but this seems to be dependent on the initiator used, since conversion was higher when using CLNa as initiator at all LL/CL ratios, except above ca. 90/10. This diminished catalytic activity of CLMgBr, as compared to CLNa, is attributed to the steric hindrance of the larger $\mathrm{CLMgBr}$ molecular size.

Figure 1(b) shows that in all cases, the molecular weight of the resulting homo- or copolymer was greater when using CLNa as initiator. Additionally, with any of the two initiators, the molecular weight of the homopolymers was greater than that of the copolymers, showing a minimum when the LL content was ca. $60 \mathrm{~mol} \%$.

As expected, upon increasing the LL concentration, the molecular weight decreases. This is attributed to the much lower reactivity of the LL anions, as compared to those of CL [12]. These results coincide with those reported by Budín et al. [11], while studying the polymerization of CL or LL, without clay.

In all cases, CLNa produced a greater conversion and also a greater molecular weight, which coincides with Odian [13], who mentions that the ring opening anionic polymerization 


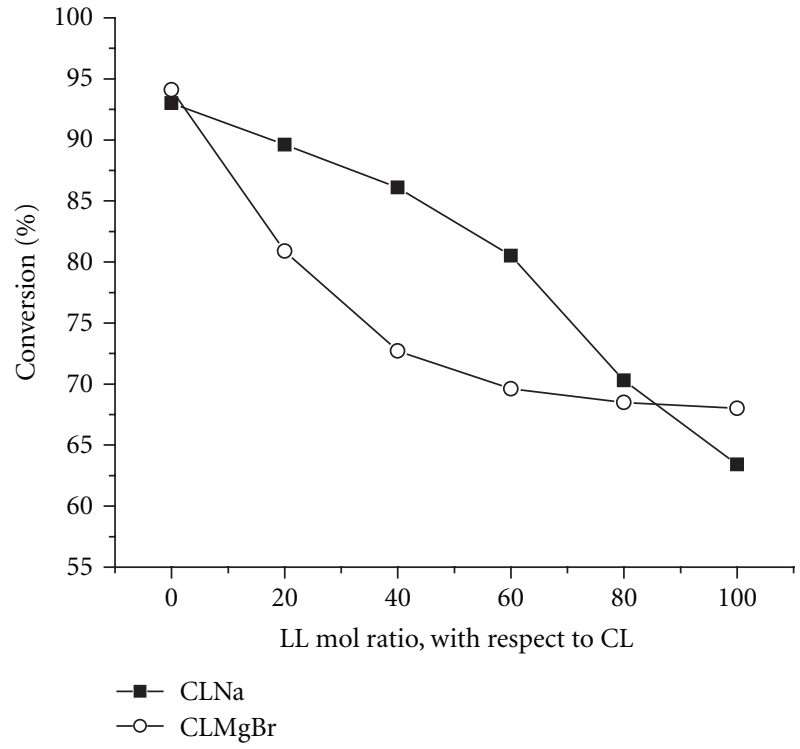

(a)

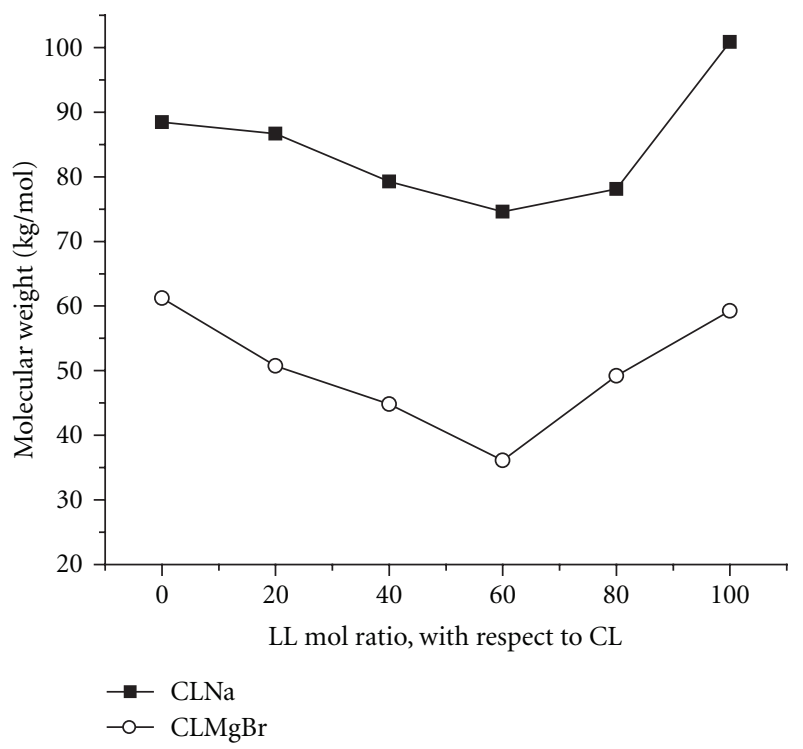

(b)

Figure 1: Effect of initiator type (CLNa or CLMgBr) and LL mol ratio on (a) conversion and (b) molecular weight during the in situ homoand copolymerization of CL, LL, and CL/LL, with $2 \mathrm{wt} \%$ of NaMMT.

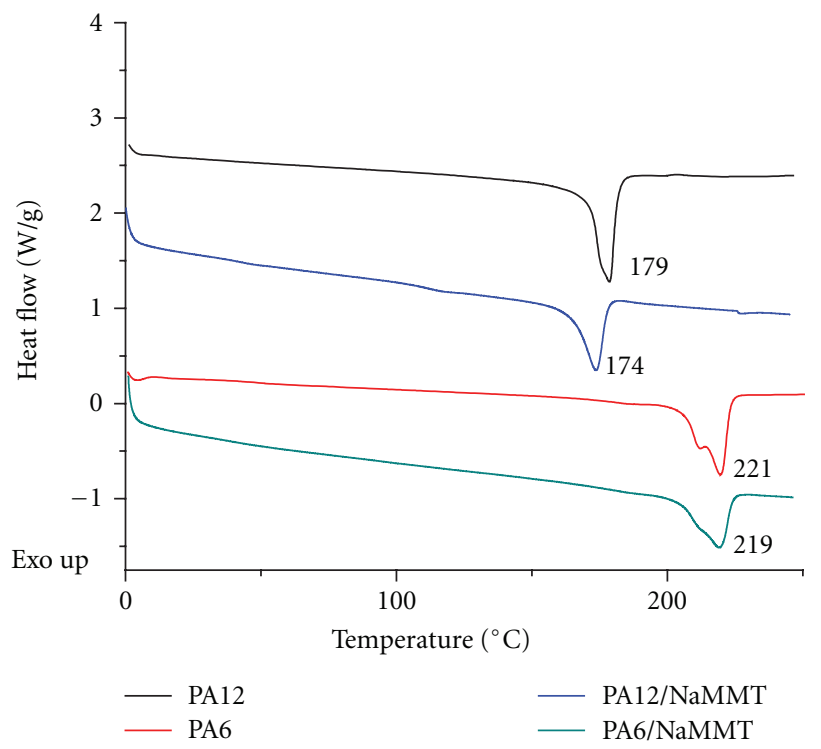

(a)

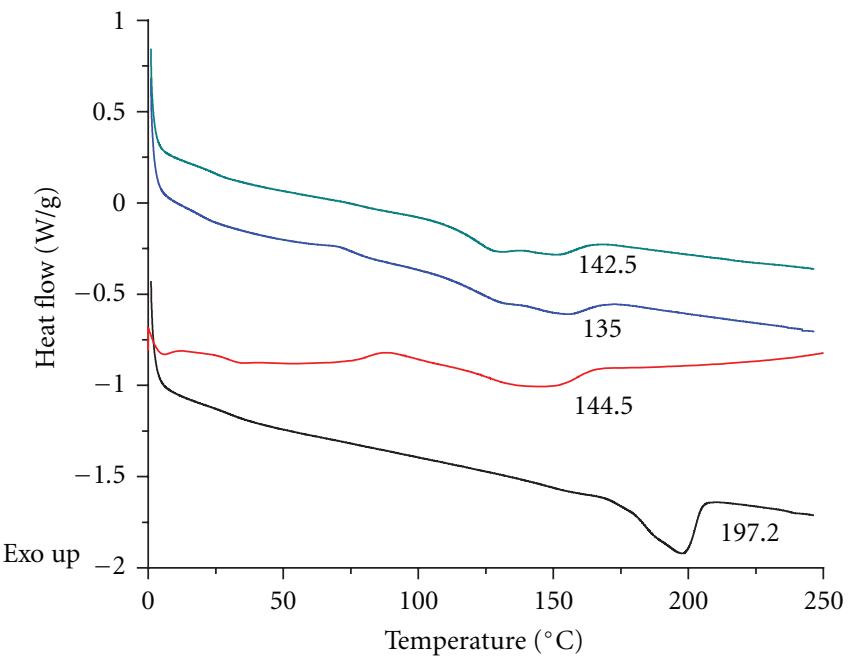

PA6:12/NaMMT $(80: 20)$

PA6:12/NaMMT $(40: 60)$ PA6:12/NaMMT $(60: 40)$ PA6:12/NaMMT $(20: 80)$

(b)

FIgURE 2: DSC curves for (a) homopolymers with and without MMT and (b) nanostructured copolymers of PA6:12 (at with 2 wt\% of nanoclay). The initiator used in this case was CLNa.

proceeds in a way that the attained molecular weight varies linearly with conversion.

In addition, the greater molecular weights, when using $\mathrm{CLNa}$, were indirectly assumed, as it was observed that during the copolymerization (CL/LL), the magnetic stirrer ceased turning after just $20 \mathrm{~s}$ of reaction when using CLNa, due to the viscosity increase, as a result of a greater molecular weight; whereas it took $35 \mathrm{~s}$ when using CLMgBr.
3.2. Thermal Properties. Figure 2 presents the effect of composition of the nanostructured polymeric compounds on the fusion temperature $T_{m}$. First, from Figure $2(a)$, it can be observed that the $T_{m}$ of the homopolymer compounds is not altered significantly, by the inclusion of the NaMMT, it remains at $221^{\circ} \mathrm{C}\left( \pm 1^{\circ} \mathrm{C}\right)$ for PA6/NaMMT and $179^{\circ} \mathrm{C}$ for Polyamide 12/NaMMT (PA12/NaMMT), in agreement with that reported elsewhere [14]. Second, from Figure 2(b), 
TABLE 1: Fusion temperature $\left(T_{m}\right)$ and enthalpy of fusion $\left(\Delta H_{m}\right)$ of the obtained homo- and copolymer compounds of CL and LL with NaMMT, using CLNa and CLMgBr.

\begin{tabular}{|c|c|c|c|c|c|}
\hline Using CLNa as initiator & LL concentration $(\% \mathrm{~mol})$ & \multicolumn{2}{|c|}{$T_{m}\left({ }^{\circ} \mathrm{C}\right)$} & \multicolumn{2}{|c|}{$\Delta H_{m}(\mathrm{~J} / \mathrm{g})$} \\
\hline PA6/NaMMT & 0 & \multicolumn{2}{|c|}{219.3} & \multicolumn{2}{|c|}{42.2} \\
\hline \multirow{4}{*}{ PA6 : 12/NaMMT } & 20 & \multicolumn{2}{|c|}{197.2} & \multicolumn{2}{|c|}{35.1} \\
\hline & 40 & \multicolumn{2}{|c|}{144.5} & \multicolumn{2}{|c|}{19.9} \\
\hline & 60 & \multicolumn{2}{|c|}{135.0} & \multicolumn{2}{|c|}{22.1} \\
\hline & 80 & \multicolumn{2}{|c|}{142.5} & \multicolumn{2}{|c|}{21.7} \\
\hline PA12/NaMMT & 100 & \multicolumn{2}{|c|}{174.0} & \multicolumn{2}{|c|}{35.1} \\
\hline Using CLMgBr as initiator & LL concentration $(\% \mathrm{~mol})$ & $T_{m_{1}}\left({ }^{\circ} \mathrm{C}\right)$ & $T_{m_{2}}\left({ }^{\circ} \mathrm{C}\right)$ & $\Delta H_{m_{1}}(\mathrm{~J} / \mathrm{g})$ & $\Delta H_{m_{2}}(\mathrm{~J} / \mathrm{g})$ \\
\hline PA6/NaMMT & 0 & 219.5 & - & 44.8 & - \\
\hline \multirow{4}{*}{ PA6 : 12/NaMMT } & 20 & 201.8 & 183.5 & 7.3 & 26.5 \\
\hline & 40 & 175.2 & 154.3 & 4.1 & 15.8 \\
\hline & 60 & 152.6 & 131.4 & - & 21.7 \\
\hline & 80 & 149.9 & 145.6 & 11.3 & 21.2 \\
\hline PA12/NaMMT & 100 & - & 172.3 & - & 31.5 \\
\hline
\end{tabular}

the $T_{m}$ of the copolymer PA6:12/NaMMT compounds, on the other hand, decreased as the concentration of LL increased, reaching a minimum $\left(135^{\circ} \mathrm{C}\right)$ at a $\mathrm{LL}$ content of $60 \mathrm{~mol} \%$.

It is also observed that the fusion temperature of the copolymers is below that of the two homopolymers. This abatement is attributed to alpha and gamma crystalline phases of Polyamide 6 (PA6) and Polyamide 12 (PA12), respectively, trying to coexist in the copolymers, as reported by Budín et al. [11]. As the LL concentration increases, the alpha crystalline phase of PA6 tends to coexist with the gamma crystalline phase of PA12, generating many crystallite imperfections. On the other hand, upon increasing the LL content in the copolymers, the crystal size and the crystalline content decrease, decreasing the fusion temperature, as reported by Kubota and Nowell [15].

Finally, it can also be observed in Figure 2(b) that the crystallinity (associated with the fusion enthalpy $\Delta H_{m}$ ) of the copolymer compounds is less than that of the homopolymers and it decreases with the concentration of LL, as can be determined from the enthalpies of fusion (Table 1).

Figure 3 shows the thermograms of the copolymers obtained using a CL/LL composition equal to 40/60. An important difference observed in the copolymers, when comparing that obtained with CLNa versus that obtained with CLMgBr initiator, is that, when using CLNa, the copolymer shows just one fusion peak, at $144.5^{\circ} \mathrm{C}$. This is indicative of a random copolymer. When using CLMgBr, on the other hand, the copolymer shows two fusion peaks, at 154.2 and $175.2^{\circ} \mathrm{C}$. This, on the other hand, is indicative of a block copolymer. These present a fair agreement with results reported by Budín et al. [11].

With respect to the fusion temperatures of the synthesized block copolymers, when using CLMgBr, it can be assumed that one block is a random block of CL (PA6) and LL (PA12) units. This randomness would hinder the formation of regular-perfect crystals, resulting in a diminished crystalline fusion temperature. The other block, on

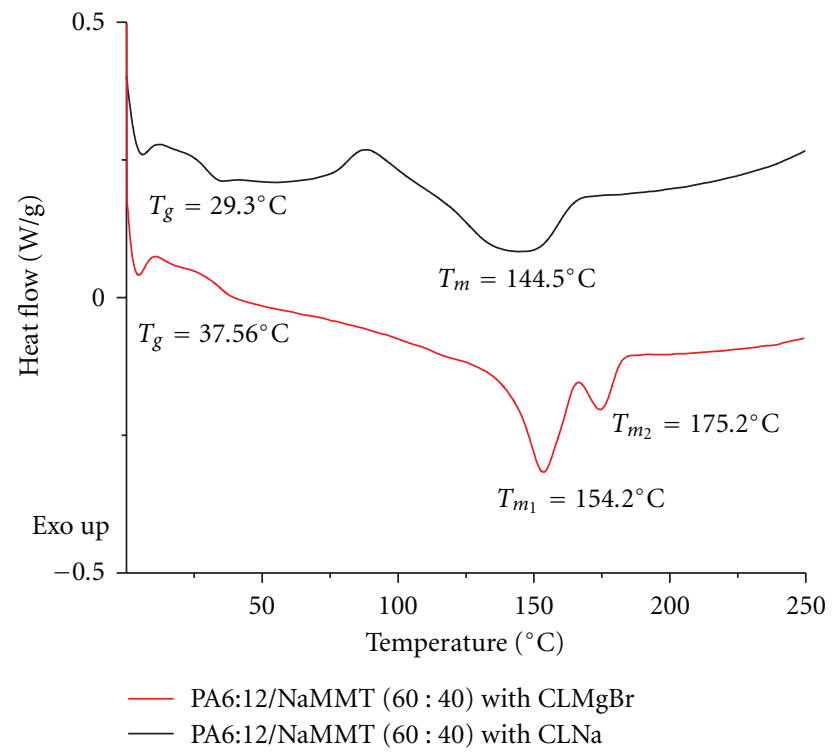

FIGURE 3: DSC curves of the two nanostructured polymer compounds of PA6: 12, with CL/LL ratio of 60/40, obtained with CLNa and with CLMgBr as initiators.

the other hand, would be composed mostly of CL units, though not sufficiently long as to show the $T_{m}$ of the PA6 homopolymer, but sufficiently long as to permit the formation of more regular-perfect crystals, with higher crystalline fusion temperature.

In addition, the insertion of the long aliphatic chains of PA12 into the structure of the PA6 in the growing PA6/PA12 copolymer chains, would give rise to a change in the crystalline type, from alpha, typical of PA6, to gamma, typical of PA12. These changes in the crystalline structure of PA would also tend to abate the fusion temperature, as has been reported elsewhere [16]. Table 1 presents the fusion temperature $\left(T_{m}\right)$ and the enthalpy of fusion $\left(\Delta H_{m}\right)$ for all the nanostructured polymer compounds studied, using 


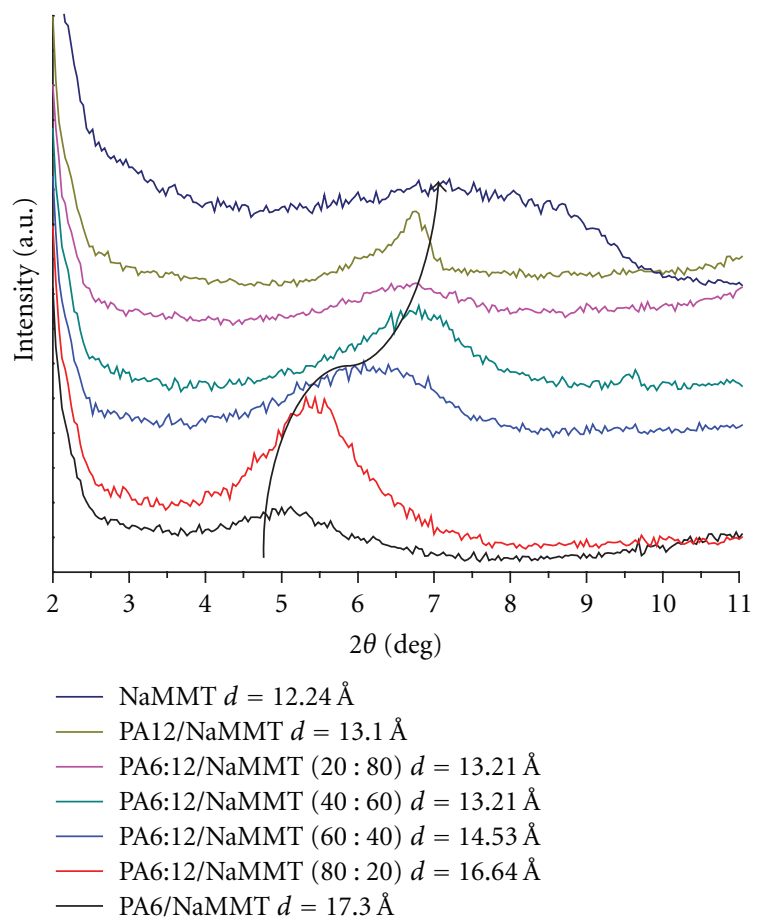

Figure 4: X-Ray diffraction curves of the homo- and copolymers of CL and LL, with $2 \mathrm{wt} \%$ of nanoclay, obtained using CLNa as initiator.

either CLNa or CLMgBr as initiators. It can be observed that the fusion temperature and the enthalpy of fusion of the copolymers are clearly affected by the increasing concentration of LL, as reported by Ricco et al. [10].

As an outcome, it can be said that the initiator type is the one that determines if the result is going to be a random or a block copolymer. In addition, the effect of LL content upon the fusion temperature of the copolymer is the same, no matter if the initiator is CLNa or CLMgBr. Finally, the addition of NaMMT has no apparent effect on the homopolymers fusion temperature $\left(\mathrm{PA} 6221^{\circ} \mathrm{C}\right.$; PA12 $179^{\circ} \mathrm{C}$ ) as shown in Figure 2(a).

3.3. Exfoliation and Dispersion of the Nanoclay. For the case of the polyamide/clay nanocompounds obtained using CLNa as initiator, Figure 4 shows that all the nanocompounds present a progressive shift of the X-Ray diffraction peak to lower $2 \theta$, with respect to that of the pure NaMMT. This indicates an increase in the gallery spacing, producing an intercalated structure, attributed primarily to the insertion of the CL and LL monomeric units into the clay galleries prior to the in situ polymerization. It is important to bear in mind that when using CLNa as initiator, there is a tendency to produce random type copolymers.

In Figure 4, it can also be observed that the diffraction peak of the PA6/NaMMT nanocompound occurs at the lowest $2 \theta$ angle, which would correspond to the largest intergallery spacing $(17.3 \AA)$. On the contrary, the peak of the PA12/NaMMT nanocompound occurs at the highest

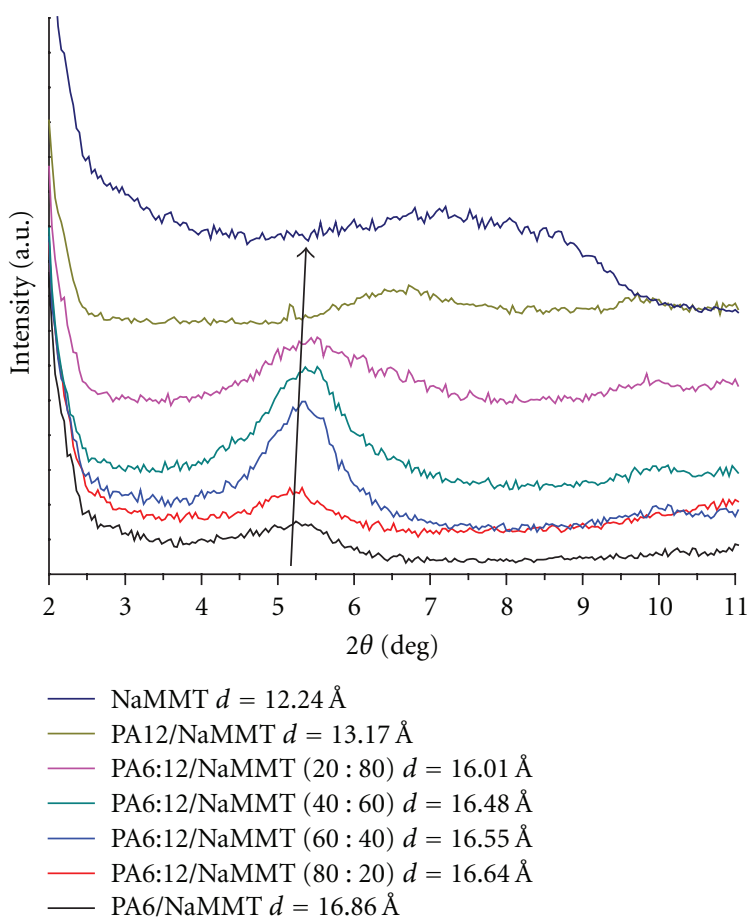

Figure 5: X-Ray diffraction curves of the homo- and copolymers of CL and LL, with $2 \mathrm{wt} \%$ of nanoclay, obtained using CLMgBr as initiator.

$2 \theta$ angle, corresponding to the smallest intergallery spacing (13.1 $\AA$ ).

In all the PA6:12/NaMMT nanocompounds, the peak occurs at higher $2 \theta$ angles as the LL content increases. That is, the intergallery spacing diminishes with the concentration of LL. These differences can be attributed to the lower polarity of PA12, compared to that of PA6, due to the longer aliphatic, nonpolar segments (12 C atoms) along its chains, as compared to the shorter aliphatic segments (6 $\mathrm{C}$ atoms) in the PA6 chains. That is, for a given polymer chain length, the PA12 shows a smaller content of the polar amide groups than the PA6. This diminished polarity of the PA12 chains makes them less compatible to the highly polar NaMMT. Thus, the decreasing intergallery spacing with increasing LL content, up to the smallest spacing for the PA12/NaMMT nanocompound.

For the case of the polyamide/clay nanocompounds obtained using CLMgBr as initiator, Figure 5 shows that all the nanocompounds present the same shift of the $\mathrm{X}$ Ray diffraction peak to lower $2 \theta$, which would correspond to an intergallery spacing of ca. $16.5 \AA$, with the exception of the PA12/NaMMT nanocompound, which presents an intergallery spacing of $13 \AA$.

When using CLMgBr as initiators, there is no effect of the LL content on the $2 \theta$ angle of the X-ray diffraction peak, as observed in Figure 4. This no-effect is assumed to be due to the block copolymer structure formed when using CLMgBr as initiator, in which case, the CL short blocks act as the highly polar PA6 homopolymer does and shows the 


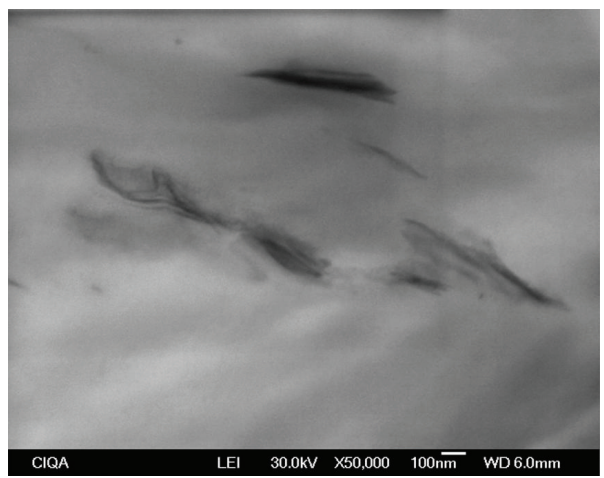

(a)

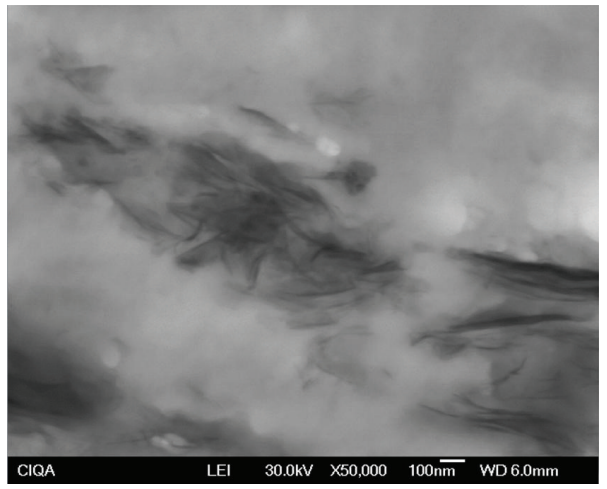

(c)

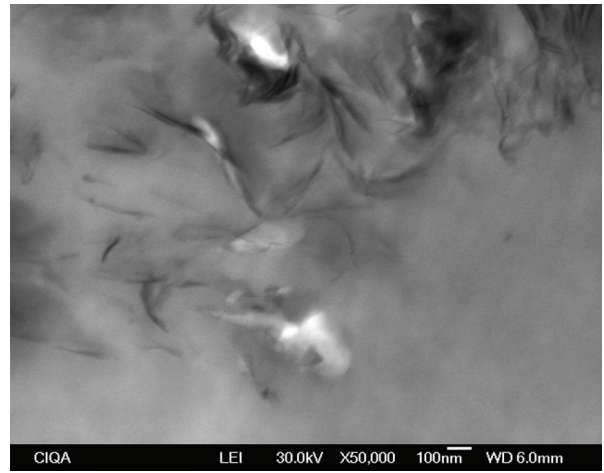

(b)

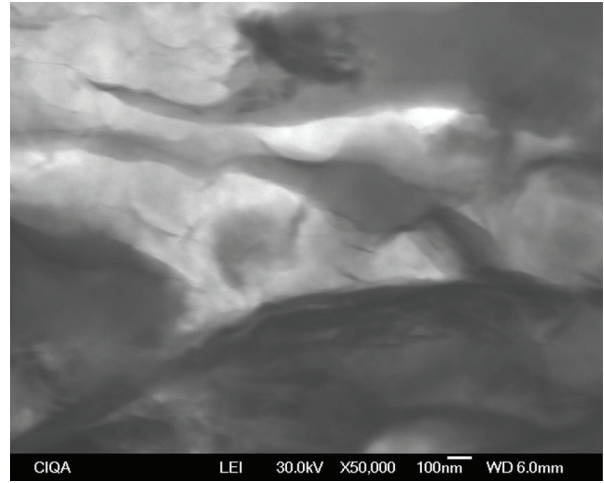

(d)

Figure 6: Electron micrographs of (a) PA6/NaMMT, (b) PA6:12/NaMMT (80:20), (c) PA6:12/NaMMT (60:40), and (d) $\underline{\text { PA12/NaMMT }}$ obtained with CLMgBr (scale bar at $100 \mathrm{~nm})$.

capability to intercalate into the clay galleries, as the highly polar PA6 homopolymer does.

The micrographs in Figures 6(a), 6(b), and 6(c) show similar levels of exfoliation/intercalation, but not that in Figure 6(d), which corresponds to the PA12/NaMMT homopolymer compound, where very little or no exfoliation/intercalation is obtained. These results agree with those obtained via the XRD analysis, where the PA6/NaMMT as well as all the PA6:12/NaMMT copolymers prepared in the presence of CLMgBr initiator, present the same intergallery spacing of ca. $16.5 \AA$, with the exception of the PA12/NaMMT homopolymer.

The incomplete clay exfoliation, even though the high affinity between the highly polar PA6 and NaMMT, can be attributed to the lack of application of any shear stresses during the preparation of the nanostructured PA compounds. It might be expected that the preparation of the same PA compounds, via reactive extrusion, could render a much higher level of clay exfoliation.

\section{Conclusions}

Homo- and copolyamide type nanocompounds were obtained, via in situ anionic polymerization of caprolactam and laurolactam with NaMMT, using two initiator types.
The use of CLNa as initiator tended to produce a random-type copolymer, whereas the use of CLMgBr tended to produce a block-type structure, which affected both the crystallinity of the copolymers and the intercalation/exfoliation of the nanoclay. In the random type copolymers, the intergallery spacing decreased with the LL content, whereas in the block type copolymer, the intergallery spacing remained the same (as that for PA6) for all the copolymers. The intergallery spacing of the PA12/NaMMT remained the lowest in all cases. The use of CLNa as initiator produced a higher conversion degree and higher molecular weight than the use of CLMgBr.

In all cases, increasing the LL content produced a decrease in the conversion degree and in the molecular weight of the resulting polymer compound.

Crystallinity of the copolymer compounds was found to be less than that of the homopolymers. Also, crystallinity was greatly affected by the LL concentration; as the LL concentration increased, crystallinity decreased, as observed from the enthalpies of fusion.

\section{Acknowledgments}

The authors thank CONACYT for its financial support to carry out this study through project 84424 . And the authors 
thank M. Sanchez, J. F. Zendejo, E. Hurtado-Suarez, and P. Siller-Flores for their technical support.

\section{References}

[1] I. Kim and J. L. White, "Anionic copolymerization of lauryl lactam and polycaprolactone to produce polyesteramide triblock copolymer," in Proceedings of the 61st Annual Technical Conference ANTEC 2003, pp. 1653-1657, May 2003.

[2] E. Šimůnková, J. Zelinger, V. Kubanek, and J. Kralicek, "The structure and physical properties of copolymers of lactams," Journal of Applied Polymer Science, vol. 21, no. 1, pp. 65-81, 1977.

[3] A. Okada, Y. Fukushima, M. Kawasumi et al., "Composite material and process to manufacturing same," 4, 739, 007 US Patent, 1988.

[4] M. Kawasumi, M. Kohzaki, Y. Kojima, A. Okada, and O. Kamigaito, "Process for producing composite material," 4, 810, 734 US Patent, 1989.

[5] Y. Kojima, A. Usuki, M. Kawasumi, A. Okada, T. Kurauchi, and O. Kamigaito, "Synthesis of nylon 6-clay hybrid by montmorillonite intercalated with $\varepsilon$-caprolactam," Journal of Polymer Science A, vol. 31, no. 4, pp. 983-986, 1993.

[6] A. Usuki, M. Kawasumi, Y. Kojima, A. Okada, T. Kurauchi, and O. Kamigaito, "Swelling behavior of montmorillonite cation exchanged for $\omega$-amino acids by $\varepsilon$-caprolactam," Journal of Materials Research, vol. 8, no. 5, pp. 1174-1178, 1993.

[7] H. P. Jung, N. K. Woo, H. S. Kye et al., "Disordering of clay layers in the nylon 6/clay nanocomposites prepared by anionic polymerization," Macromolecular Research, vol. 13, no. 5, pp. 367-372, 2005.

[8] A. Liu, T. Xie, and G. Yang, "Comparison of polyamide-6 nanocomposites based on pristine and organic montmorillonite obtained via anionic ring-opening polymerization," Macromolecular Chemistry and Physics, vol. 207, no. 13, pp. 1174-1181, 2006.

[9] R. Ahmed and S. J. Lee, "Polyamide-clay nanocomposites and their non-linear viscoelastic characterization," Journal of Advanced Materials, vol. 2, pp. 127-133, 2007.

[10] L. Ricco, S. Russo, G. Orefice, and F. Riva, "Caprolactamlaurolactam copolymers: fast activated anionic synthesis, thermal properties and structural investigations," Macromolecular Chemistry and Physics, vol. 202, no. 10, pp. 2114-2121, 2001.

[11] J. Budín, J. Brožek, and J. Roda, "Polymerization of lactams, 96* anionic copolymerization of $\varepsilon$-caprolactam with $\omega$ laurolactam," Polymer, vol. 47, no. 1, pp. 140-147, 2006.

[12] T. M. Frunze, V. A. Kotel'nikov, V. V. Kurashev, S. L. Ivanova, L. I. Komarova, and V. V. Korshak, "The relative reactivities of $\varepsilon$-caprolactam and $\omega$-dodecalactam in activated anionic copolymerization," Polymer Science U.S.S.R., vol. 18, no. 2, pp. 348-353, 1976.

[13] G. Odian, Principles of Polymerization, Wiley Intersciences, 3rd edition, 1991.

[14] J. Brandrup, E. H. Immergut, E. A. Grulke, A. Abe, and D. R. Bloch, Polymer Handbook, John Wiley \& Sons, 4th edition, 2003.

[15] H. Kubota and J. B. Nowell, "Changes in the morphology of cast nylon 6 through copolymerization," , Journal of Applied Polymer Science, vol. 19, no. 6, pp. 1521-1538, 1975.

[16] D. P. Garner and P. D. Fasulo, "Effect of composition on the properties of nylon 612 copolymers," Journal of Applied Polymer Science, vol. 36, no. 3, pp. 495-509, 1988. 

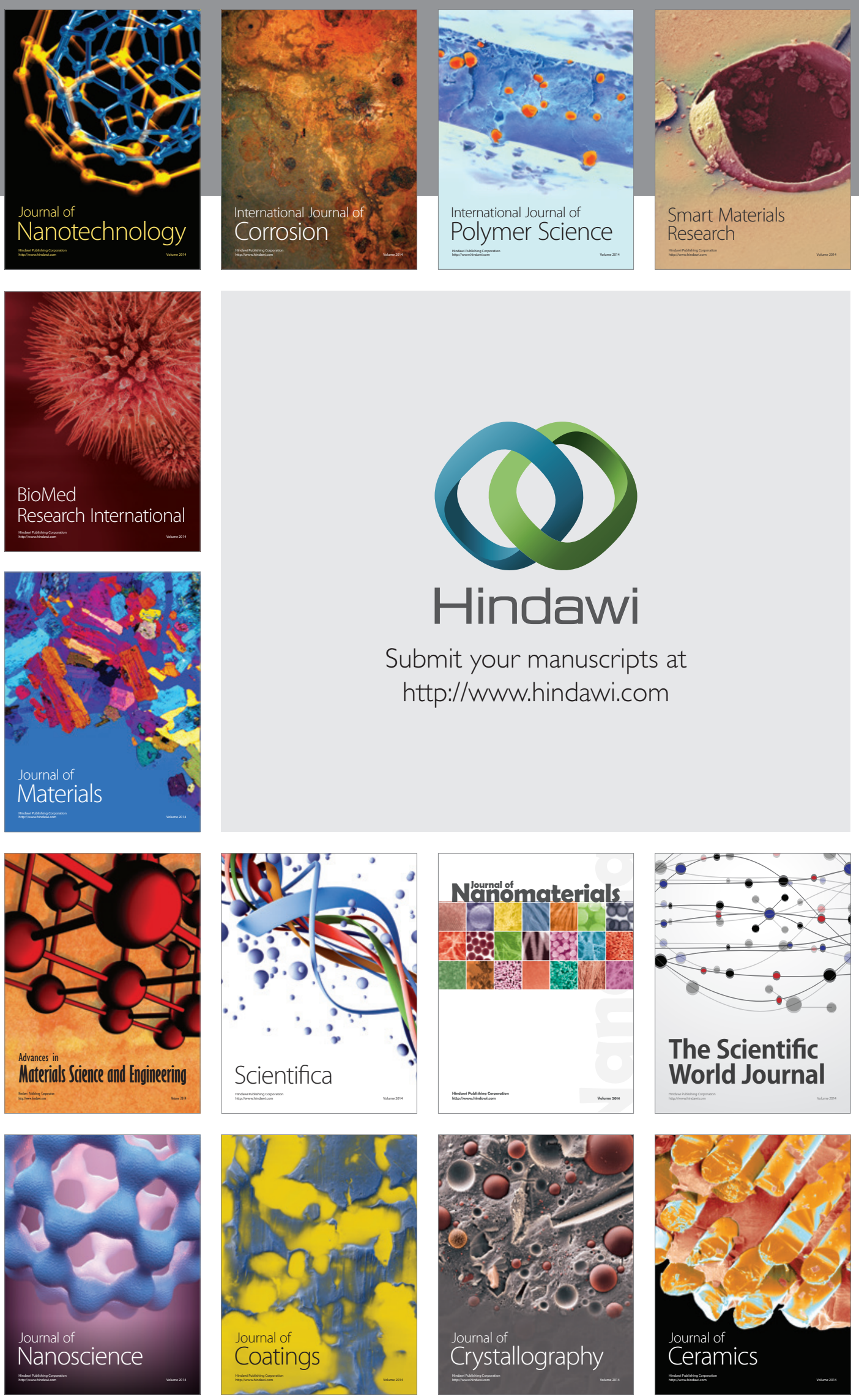

The Scientific World Journal

Submit your manuscripts at

http://www.hindawi.com

\section{World Journal}

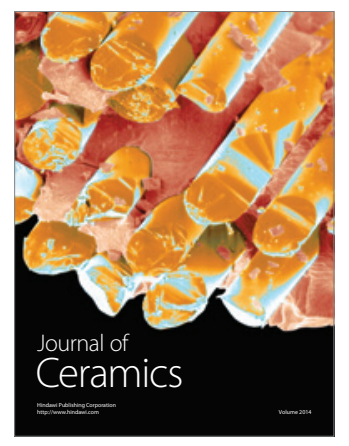

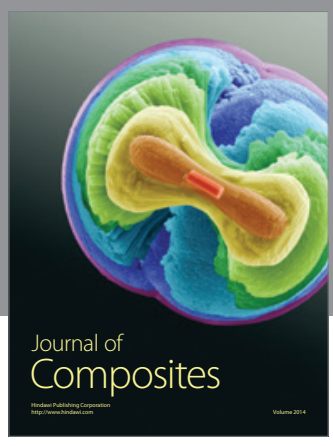
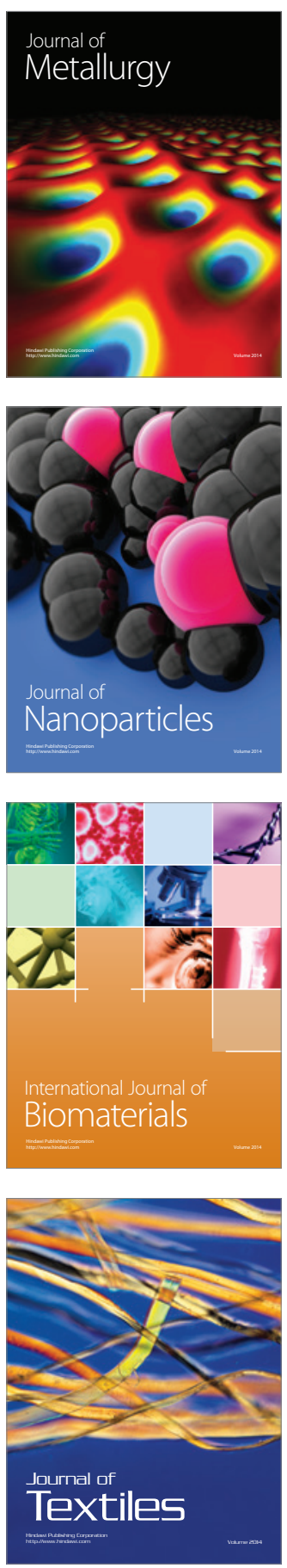